\title{
Assessment of Knowledge and Skills of Phlebotomy Technique among Nursing Staffs of a Teaching Hospital
}

\author{
Usha Adiga $^{1}$. Sachidananda Adiga ${ }^{2}$ \\ ${ }^{1}$ Professor, Department of Biochemistry, KSHEMA, Mangalore \\ ${ }^{2}$ Professor, Department of Pharmacology, KSHEMA, Mangalore
}

\begin{abstract}
:
Introduction: Phlebotomy is a commonly done invasive technique, performed either for diagnostic or therapeutic purpose. A thorough knowledge and skills are to be ensured in the health care professionals who carry out this procedure regularly so as to ensure patient safety and minimize pre analytical errors in laboratory investigations. Aim of the present study was to assess the theoretical knowledge and practical skills of nursing staffs to carry out the phlebotomy procedure.

Methodology: A validated questionnaire study involving seventy four nursing staffs of the medical college teaching hospital was conducted. They were divided in to three groups belonging to different age groups, like 19-30 yr, 31-45 yr and 45-60 yr. They were also classified based on their number of years of experience, as 0-5 yr,6-15 yr and more than $15 \mathrm{yr}$ of experience. A validated questionnaire consisting of 10 knowledge assessing questions, 7 skills assessing questions and 3 information on demographic profile was administered to them. Each question carried one mark each, total score being 17, knowledge score being 10 and skills/practice score being 7. Statistical analysis was carried out by using Graph pad Instat software. One way ANNOVA was used to compare the scores, total, knowledge and practice scores between different groups. Knowledge and skills components of different groups were compared by using Student s Unpaired ' $t$ ' test. Descriptive statistics is used to calculate percentage of correct answers.

Results: Definition of hemolysis was correctly answered by $66 \%$ nurses. $52.7 \%$ nursing staffs were aware that hemolysis can occur not only during sampling, but any time during the laboratory procedure.66.2\% thought that forcing the blood in to tubes by pushing the plunger in order to fill the tubes is the most frequent cause of hemolysis. $37.8 \%$ of nurses were aware that less than half full tube can frequently cause hemolysis. The relationship between the needle gauge size and hemolysis was known only by $18.9 \%$ nurses. $70.27 \%$ wrongly thought that isopropyl or ethyl alcohol used as disinfectant can cause hemolysis. $71.6 \%$ were aware that hemolysis can influence the lab reports. However there wasn't any statistical significant difference between the scores in different groups.

Conclusion: We conclude from our study that nursing staffs of our teaching hospital inspite of being experienced, lack in knowledge and skills of phlebotomy technique and factors contributing to pre analytical errors necessitates an intervention, in the form of training program.
\end{abstract}

Keywords: phlebotomy, knowledge, skills, hemolysis

\section{Introduction}

In healthcare system, venous blood collection is one of the most commonly done invasive procedures. Even though it is thought to be safe procedure, it is associated with its own risks $(1,2)$. To perform phlebotomy successfully , a theoretical knowledge as well as practical skills are required (3).Lack of knowledge or skills may lead to errors in the procedure which might make patients suffer due to injuries (4).Errors occur as the lab personnel do not always follow guidelines or not updated with the recent advances in the technique(5-9). Lack of time and lack of support from the higher authorities in providing the necessary infrastructure contributes to the loop holes in carrying out the procedure. It is very important to collect biological samples correctly to ensure accurate analysis. Blood investigation reports are very crucial in decision making, any error during sampling may have serious consequences. So it is very essential to train the laboratory personnel who are involved in sample collection and handling. A few studies are available which measured quality of venous blood sampling and knowledge of phlebotomists in carrying out the procedure (3,5-7).However a few such studies are available in Indian settings, to the best of our knowledge.

Aim of the present study was to assess the theoretical knowledge and practical skills of nursing staffs to carry out the phlebotomy procedure. 


\section{Methodology}

The questionnaire study was conducted in Karwar Institute of Medical Sciences, Karwar. Seventy four nursing staffs of the medical college teaching hospital were included in the study. They were divided in to three groups belonging to different age groups, like 19-30 yr, 31-45 yr and 45-60 yr. Another division was made based on their number of years of experience as those having 0-5 yr,6-15 yr and more than $15 \mathrm{yr}$ of experience. A validated questionnaire involving $20 \mathrm{MCQs}$ was administered to them. Out of twenty questions, 10 questions assessed knowledge domain,7 were on skills and three questions were framed to gather information of their demographic profiles. Each question carried one mark each, total score being 17, knowledge score being 10 and skills/practice score being 7.The scores are represented as they are obtained while comparing in different groups. But when knowledge vs practice scores are compared, uniformity is maintained by converting total practice score to 10 .

The questions addressing cognitive (knowledge) domain were definitions and causes of hemolysis, relationship between risk of hemolysis and forcing of blood in to tubes, effect of turbulent flow of blood, needle gauge size, disinfectant used and quantity of blood drawn in to tubes on hemolysis. Psychomotor domain (skills) of nurses was assessed through questions like what would be their first action when they notice a hemolysed sample. Awareness of other venepuncture skills like tourniquet application time, preferred site for blood collection, number of attempts for venepuncture to cause hemolysis, the method of mixing blood with the anticoagulant were assessed.

Statistical analysis was carried out by using Graph pad Instat software. One way ANNOVA was used to compare the scores, total, knowledge and practice scores between different groups. Knowledge and skills components of different groups were compared by using Student's Unpaired ' $t$ ' test. Descriptive statistics is used to calculate percentage of correct answers.

\section{Results}

We observed an increase in total, knowledge and practice scores with the advancing age, highest score being in the senior nurses(45-60 yr) as compared to those in other groups. However the differences in the scores were statistically significant (Table 1). When the scores were compared in groups based on the number of years of experience ,total and knowledge scores were highest in nurses having 6-15 years of experience, whereas practice score was highest among senior most nurses(more than 15 years of experience).However the differences were not statistically significant (Table 2).

Table 1: Comparison of scores in different age groups

\begin{tabular}{|l|l|l|l|l|}
\hline & $\begin{array}{l}19-30 \mathrm{yr} \\
(\mathrm{n}=32)\end{array}$ & $\begin{array}{l}31-45 \mathrm{yr} \\
(\mathrm{n}=24)\end{array}$ & $\begin{array}{l}45-60 \mathrm{yr} \\
(\mathrm{n}=18)\end{array}$ & P value \\
\hline Total score (Out of 17) & $8 \pm 0.41$ & $8.58 \pm 0.55$ & $8.89 \pm 0.53$ & 0.58 \\
\hline Knowledge score(Out of 10) & $4.47 \pm 0.31$ & $4.71 \pm 0.39$ & $4.94 \pm 0.39$ & 0.7 \\
\hline Practice(Out of 7) & $3.53 \pm 0.24$ & $3.87 \pm 0.3$ & $3.94 \pm 0.29$ & 0.6 \\
\hline
\end{tabular}

Table 2: Comparison of scores in different groups based on number of years of experience

\begin{tabular}{|l|l|l|l|l|}
\hline & $\begin{array}{l}0-5 \mathrm{yr} \\
(\mathrm{n}=26)\end{array}$ & $\begin{array}{l}6-15 \mathrm{yr} \\
(\mathrm{n}=22)\end{array}$ & $\begin{array}{l}>15 \mathrm{yr} \\
(\mathrm{n}=26)\end{array}$ & P value \\
\hline Total score (Out of 17) & $7.65 \pm 0.46$ & $8.95 \pm 0.48$ & $8.69 \pm 0.5$ & 0.16 \\
\hline Knowledge score(Out of 10) & $4.07 \pm 0.36$ & $5.18 \pm 0.42$ & $4.81 \pm 0.36$ & 0.12 \\
\hline Practice(Out of 7) & $3.58 \pm 0.28$ & $3.77 \pm 0.32$ & $3.88 \pm 0.24$ & 0.77 \\
\hline
\end{tabular}

Table 3: Comparison of knowledge Vs practice in different age groups

\begin{tabular}{|l|l|l|l|}
\hline Age groups & Knowledge scores & Practice scores & P value \\
\hline $19-30 \mathrm{yr}$ & $4.46 \pm 0.37$ & $5.04 \pm 0.34$ & 0.25 \\
\hline $31-45 \mathrm{yr}$ & $4.71 \pm 0.39$ & $5.53 \pm 0.43$ & 0.16 \\
\hline $45-60 \mathrm{yr}$ & $4.94 \pm 0.39$ & $5.52 \pm 0.42$ & 0.24 \\
\hline
\end{tabular}

\section{Discussion}

We observed that there was no significant difference in the total,knowledge and practice scores between the groups based either on age or number of years of experience (Table $1 \& 2$ ). It was also noted that the difference in cognitive versus psychomotor domain scores was statistically insignificant. However we observed an insufficient knowledge and skills regarding phlebotomy techniques among nurses. Similar studies were carried out by Milutinovic et al (10) and Dorotic et al (11).

Majority of the questions assessing the knowledge domain were correctly answered. Definition of hemolysis was correctly answered by $66 \%$ nurses.52.7\% nursing staffs were aware that hemolysis can occur not only during sampling, but any time during the laboratory procedure.66.2\% thought that forcing the blood in to tubes by pushing the plunger in order to fill the tubes is the most frequent cause of hemolysis. Koebke et al 
opined that hemolysis mainly depends on the way blood is forced through a fine needle(12). 56.7\% thought correctly that turbulent flow of blood can lead to hemolysis. Yen and colleagues suggested that turbulent viscous shear stress on RBCs causes damage and hemolysis (13). Only 37.8\% of nurses were aware than less than half full tube can frequently causes hemolysis. The relationship between the needle gauge size and hemolysis was known only by $18.9 \%$ nurses. A meta analysis report by Heyer et al suggests that larger needles ( $\leq 21$ gauge) may reduce hemolysis by reducing stress and/or turbulence for the red blood cells as the specimen is collected (14).It concludes that antecubital fossa provides access to larger veins and use of bigger needles poses lesser risk of hemolysis.

$70.27 \%$ wrongly thought that isopropyl or ethyl alcohol used as disinfectant can cause hemolysis, if not completely dried. $71.6 \%$ were aware that hemolysis can influence the lab reports, but only $40 \%$ are aware of the fact that serum potassium levels are elevated by hemolysis. Lippi and colleagues reported that hemolysis influences routine clinical chemistry analytes (15).The study reports that hemolysis overestimates liver transaminases, creatine kinase, iron, lactate dehydrogenase, lipase, magnesium, phosphorous, potassium and urea. It is also reported that albumin, alkaline phosphatase, chloride, gamma glutamyl transferase, glucose and sodium were decreased as a result of hemolysis. When we assessed the psychomotor domain (skills), we found a similar response as the cognitive domain.55.4\% nurses thought that it is essential to inform the doctor regarding the necessity to repeat sampling. Majority of them $(78.38 \%)$ were aware that tourniquet should be applied for less than or equal to one minute. Rest were under the impression that it is more than a minute. Saleem et al reported in a study that tourniquet time and number of attempts at venipuncture were associated with hemolysis (16).As tourniquet constricts the blood vessels and causes hemolysis, should be applied for less than a minute. Only 50\% nurses thought that blood should be drawn distal to the elbow to avoid hemolysis. Least number $(35.14 \%)$ of nurses were aware that if there is a hematoma, sample should be collected area below hematoma to avoid hemolysis. Basic knowledge like vein should be palpated with index finger was there only in $35.7 \%$ of them. $48.65 \%$ of the staff were aware that specimen should be mixed with anticoagulant by shaking the tube in horizontal position. Adequate mixing of blood with anticoagulant or preservative is ensured by a slow rolling wrist motion to invert the tube gently five or six times .If not inverted microscopic clots are formed. Rapid wrist motion or vigorous shaking may contribute to hemolysis.

\section{Conclusion}

We could conclude from our study that nursing staffs of our teaching hospital inspite of being experienced, lack knowledge and skills regarding phlebotomy technique. We also feel that it is very essential to bring an awareness regarding causes of hemolysis during sample collection and factors contributing to pre analytical errors necessitates an intervention, in the form of training program.

\section{References}

[1]. Fang L, Fang S, Chung Y, Chien S. Collecting factors related to the hemolysis of blood specimens. J Clin Nurs 2008;17:2343-51.

[2]. Fujii C, Ishii H, Takanishi A. Safe venepuncture techniques using a vacuum tube system. Int J Nurs Pract 2013;19 (3):11-9.

[3]. Bjork IT: What constitutes a nursing practical skill? West J Nurs Res 1999;21:51-63.

[4]. Plebani M: Errors in clinical laboratories or errors in laboratory medicine? Clin Chem Lab Med 2006, 44:750-759.

[5]. Söderberg J, Wallin O, Grankvist K, Brulin C: Is the test result correct? A questionnaire study of blood collection practices in primary health care. J Eval Clin Pract 2010; 16:707-711.

[6]. Söderberg J, Brulin C, Grankvist K, Wallin O: Preanalytical errors in primary healthcare: a questionnaire study of information search procedures, test request management and test tube labelling. Clin Chem Lab Med 2009; 47:195-201.

[7]. Wallin O, Soderberg J, Van Guelpen B, Stenlund H, Grankvist K, Brulin C: Blood sample collection and patient identification demand improvement: a questionnaire study of preanalytical practices in hospital wards and laboratories. Scand J Caring Sci 2010; 24:581-591.

[8]. Wallin O, Soderberg J, Van Guelpen B, Stenlund H, Grankvist K, Brulin C: Preanalytical venous blood sampling practices demand improvement - a survey of test-request management, test-tube labelling and information search procedures. Clin Chim Acta 2008; 391:91-97.

[9]. Grol R, Grimshaw J: From best evidence to best practice: effective implementation of change in patients' care. Lancet 2003; 362:1225-1230.

[10]. Dragana Milutinovic, Ilija Andrijevic, Milijana Licina, Ljiljana Andrijevic. Confidence level in venipuncture and knowledge on causes of in vitro hemolysis among healthcare professionals. Biochemia Medica 2015;25(3):401-9

[11]. Adrijana Dorotic, Dragana Antoncic, Vanja Radisic Biljak, Dara Nedic, Andjelo Beletic. Hemolysis from a nurses' standpoint survey from four Croatian hospitals. Biochemia Medica 2015;25(3):393-400

[12]. Koebke J, McFarland E, Mein M, Winkler B, Slockbower JM, Blumenfeld TA, eds. Collection and handling of laboratory specimens .Philadelphia:JB Lippincott,1983:32-4

[13]. Yen JH, Chen SF, Chern MK, duPC. The effect of turbulent viscous shear stress on red blood cells hemolysis. J Arif Organs 2014;17(2):178-85.

[14]. Heyer NJ, Derzon JH, Winges L, Shaw C, Mass D, Christenson RH, Snyder SR, Epner P, Liebow EB. Effectiveness of practices to reduce blood sample hemolysis in EDs:A lab medicine best practices systematic review and meta analysis.Clin Bochem 2012;45(13-14):1012-32

[15]. Allegato-Giuseppe Lippi, Gian Luka Salvagno, Martina Montagnana, Giorgio Brocco, Gian Cesare Guidi. Influence of hemolysis on routine clinical chemistry testing. Clin chem Lab med 2006;44(3):311-16.

[16]. Saleem S, Manvi V, Chadwick MA, Creanor S, Ayling RM. A prospective study of causes of hemolysis during venepuncture: tourniquet time should be kept to minimum. Ann Clin Biochem 2009;46(3):244-6. 